\title{
Reductionism and Complex Thinking in ERP Systems Implementations
}

\author{
Thomaz Wood Jr. \\ Miguel Pinto Caldas
}

\section{RESUMO}

Este artigo contrasta pensamento complexo e reducionismo em processos amplos de transformação organizacional, focalizando a onda dos Sistemas Empresariais (ERP). Implementações de ERP têm representado imensos investimentos para empresas em todo o mundo nos últimos anos, e têm sido promovidas como panacéias gerenciais. Não surpreende que muitas implementações não atendam tais expectativas. Para aqueles que lidam com mudança organizacional, o fenômeno ERP deve soar desconfortavelmente familiar. Este estudo introduz o fenômeno, apresenta um breve resumo de uma pesquisa exploratória de campo envolvendo 28 experiências de implementação, e discute o conceito de reducionismo no âmbito das implantações de ERP. Argumenta-se que, pela aplicação do pensamento complexo, no lugar do tecno-reducionismo e do reducionismo sistêmico, podem-se abrir novas trilhas para explicar o fenômeno.

Palavras-chaves: sistemas empresariais; modas gerenciais; reducionismo; pensamento complexo.

\begin{abstract}
This paper contrasts complex thinking and reductionism during broad organizational transformation processes, focusing on Enterprise Resource Planning (ERP) rage. ERP implementations have resulted in huge investments for companies around the globe over the last few years, and have been promoted as a management panacea. Not surprisingly, many implementations have failed to live up to expectations. For those dealing with organizational change, the ERP phenomenon may sound uncomfortably familiar. This study introduces the phenomenon, presents a summary of an exploratory field survey of 28 implementation experiences and discusses reductionism in the realm of ERP implementations. It is argued that by applying complex thinking, rather than technoreductionism and systemic-reductionism, we may open new avenues towards explaining the phenomenon.
\end{abstract}

Key words: enterprise resource planning systems; management fads; reductionism; complex thinking. 


\section{INTRODUCTION: Breaking the WaVes}

The introduction of managerial innovations into contemporary organizations is an issue of major importance for theorists and practitioners, and one that has been covered extensively in both managerial and scholarly literature (e.g., Rogers, 1983; Van de Ven, 1986). The topic has also attracted the attention of executives working on the problem of competitiveness, and it has become significant for academics as administrative innovations are increasingly gaining the status of management fads (e.g., Abrahamson, 1991, 1996; Gill and Whittle, 1992).

Indeed, the business world seems to be living through accelerating waves of innovation adoption. Novelties succeed each other ceaselessly, often devoid of an adequate appraisal of their benefits to organizations. Significantly, among consultants and executives, the expression to surf the waves of change has become popular over the last few years (see Morgan, 1986). Such an expression portrays the linear and transitory nature intrinsic to the movements of new managerial technology introduction into organizations, as much as it helps to characterize it.

ERP systems, one of the most striking of those managerial waves, are comprehensive information technology packages built on the promise that all critical information should be totally integrated into one single information database. In fact, anyone who has wandered around organizations in the past year or two is very likely to have heard a great deal about ERP systems, their incontestable benefits and the urgent need for their implementation.

However, in practice, things have worked out slightly differently, and for many organizations the golden dream has become a nightmare. One is frequently bound nowadays to witness such horror stories about ERP implementations, and can thus quickly identify a few problems common to several unfortunate implementations:

- firstly, the context and mechanisms that permeate the decisions on ERP adoption and implementation strategy tend to be very much like those related to the adoption of managerial fads and fashions, which bring about flaws such as significant political and institutional pressures to conform coupled with high emotional content in decision making;

. secondly, the typical ERP implementation approach is inclined to disregard critical factors related to organizational change and transformation management; and 
. thirdly, the results obtained from the ERP implementation can often be disappointing and incompatible with the high investments that are usually made.

In the authors' own experience, prevalent visions of the change process that we have termed techno-reductionism and systemic-reductionism have also been noticeable among executives and consultants involved with ERP implementations.

Reductionism can be generically defined as the classical approach in analytical thinking, put together mostly by Descartes, which divides the whole into parts, and then focuses on each part separately. During ERP implementations, technoreductionism implies reducing the whole to a part, conceiving the entire process as a mere implementation of an information technology (IT) tool. By the same token, systemic-reductionism entails to reduce a complex system to a subset of its parts, visualizing the whole process solely as the introduction of a new IT device, accompanied by some process reengineering, communication and training on the side.

However, for those dealing with organizational change, the ERP phenomenonand some of its pitfalls - may sound uncomfortably familiar. Change theorists and practitioners have actually witnessed the coming and going of management fads and panaceas for quite some time, and have struggled not only to keep up with them, but to foster organizational change amid the frenzy management panacea tend to generate.

We believe that by applying complex thinking rather than the prevailing techno and systemic-reductionism, we may open new avenues towards explaining those processes. This paper addresses reductionism in organizational transformation, and the perils it presents to change processes.

We argue that, in order to understand large organizational interventions such as wide-ranging ERP implementations, and to effectively favor organizational development in their midst, one should first visualize their broad organizational determinants and implications, as well as their transformational nature. In other words, with the case at hand, one should realize that ERP is not only about IT, or IT plus reengineering: it is about the relation between IT and change.

The paper is structured as follows:

. in section two we present a brief introduction to the ERP phenomenon;

in section three we summarize methods and results of an exploratory field survey involving 28 cases of ERP implementation; 
. in section four we propose a broader, alternative, perspective on the ERP phenomenon;

- section five contains a brief discussion on reductionism and complex thinking, in which we speculate on possible causes for the predominance of reductionist approaches during ERP implementations; and

. in section five we present our final comments on the subject.

\section{A Brief Introduction to the (NOT SO) Wonderful World of ERP}

ERP has become a fixed idea for managers all over the world. Its attributes bring about futuristic fantasies. Business media has dedicated cover pages and special reports to it. Users publicize its virtues and show off the millions of dollars that its implementations have saved for their organizations. Consultants are all prescribing it, and companies all over the world are adopting it. Ultimately, ERP seems to have conquered hearts and minds!

If one takes a typical vendor's discourse, it will go approximately as follows:

"The investment will be huge, and the implementation will be no rose garden. But, at the end of the journey, the entire organization will be completely integrated in one single system. It will only take a consumer pulling a product out of a supermarket shelf to trigger a complex web of system connections, which will command inventory supply, invoices, production planning, supplier ordering, and so on. The new system will improve information, speed up decision making, reduce costs, multiply net profits, and, of course, keep everything under control. A true finding! If one wants to remain competitive, one simply can not stay out of it".

Between mid-1997 and mid-1998, the market for software vendors alone was estimated at US $\$ 10$ billion. Another US\$20 billion in business were calculated in management consulting and supplementary software, and up to US $\$ 10$ billion in hardware and accessories (BusinessWeek, 1998). By the end of 1998, software vendors alone were computing annual sales of more than US\$15 billion and specialists forecasted the entire enterprise software market to grow up to US\$70 billion by the end of 2002 (AMR Research, 1998).

The expectations of ERP's impact on organizations are enormous, as well as the sum of investments involved. The implementation budget for medium-sized 
organizations can run up to US\$20 million, and large multinational firms have announced investments of almost US\$500 million (Davenport, 1998).

ERP can be implemented, with adjustments, in any organization. Economies of scale can bring an important cost advantage over solutions tailored for each company. Such systems are capable - or so it is said - of integrating the management of the entire organization, speeding up decision making, and allowing organizational performance to be monitored in real time.

But, for those who may venture onto the road, at first several implementation difficulties may arise: inexperienced consultants, unprepared users, chronic delays, and significant budget overruns. Then the organization may realize that its main business processes will not fit the new system: the organization has to be adapted to the system's needs. Or even worse: after twelve months of concentrated energy spent on the implementation effort, important decisions may have to be delayed, clients may complain, and shareholders can get impatient. The route to ERP may not always be as smooth as one expected it to be.

A central problem in this matter is that decisions regarding the implementation of such systems have been frequently made in an atmosphere of great urgency, created by both the promotional strength of vendors, and the political agenda of executives within organizations. Options end up being limited to the leading software vendors - such as SAP, PeopleSoft, J.D. Edwards and BAAN - on the one hand, and to the largest consulting firms on the other. Ultimately, many organizations are allocating a lot of time, money and energy to poorly elaborated projects.

ERP implementations generally constitute immense projects, which seldom take less than 12 months, and which mobilize large multidisciplinary, dedicated teams, normally comprising information technology specialists, key users and operations personnel, as well as consultants with process redesign and change management skills. Those who make it to the end of this marathon tend to celebrate, but truly without guarantees that it was either worth it or that the benefits foreseen at the outset will justify the high price that the process has entailed.

There seems to be no doubt that the effective management of information in an organization nowadays can be a source of competitive advantage. In fact, organizations such as American Airlines, Federal Express and Amazon Books owe part of their success to the intelligent use of information. But not all the examples are so clear cut, and the relationship between information technology and competitive advantage in most organizations is difficult to determine. According to some specialists (e.g., McGee, Pyburn and Pruzak, 1993), extensive investments in information technology have failed to produce all of its transformation potential 
and may not have generated significant financial returns. In fact, the idea that complex problems can be rapidly resolved by investing in sophisticated machinery is quite seductive. However, at the heart of such a notion lies an almost irrational belief that technology in general and information technology in particular will provide a cure for all evils.

ERP implementations involve, in truth, broad organizational transformation processes, with significant implications to the organization's management model, organization structure, management style and culture, and particularly, to people. Unfortunately, many executives and consultants still have not realized the scope and the significance of the organizational impacts that such implications can give rise to. Much of what is reported and written in the business media on the subject is known to be, at best, wishful thinking. In the meantime, a few consultants and academics (e.g., Correa, 1998; Davenport, 1998) are beginning to disrupt a certain misinformed unanimity that has been built up around the subject, and some have even ventured to make a discouraging prognosis about the future of such systems (Carvalho, 1998).

\section{News from the Front}

In this section we summarize the methodology and main findings of an exploratory field survey involving ERP implementations.

\section{Research Design and Methodology}

The field survey involved the investigation of ERP implementation processes in 40 organizations. Trained researchers conducted 107 interviews in these 40 organizations. The (non-random) sample included organizations from a large array of industries: pharmaceutical, chemical, textile, telecommunications, automotive, consumer goods, electronics, financial etc. Most of the organizations were large or mid-sized. A significant proportion (85\%) was comprised of subsidiaries of foreign multinational corporations, which could benefit from the previous experience of the implementations conducted by the home operations or other subsidiaries.

The initial sample was filtered using a validation protocol, resulting in 28 organizations and 56 valid interviews. All organizations in the final sample had completed an ERP implementation. In the final sample, each organization was represented by two of its members: one had to be an implementation agent (an 
employee of the organization who had coordinated or intensively participated in the ERP implementation), and the other had to be a key user (an employee of the organization that made significant use of the system).

The interview script used in the field survey contained 55 questions -7 multiplechoice questions, 45 Likert-scaled questions, and 3 open questions - and was divided in five segments: (1) firm and respondent identification; (2) reasons for implementing ERP; (3) implementation approach; (4) implementation results; and (5) implementation assessment. All responses were then classified and analyzed. The following subsection presents a summary of the major findings.

\section{Findings and Comments}

\section{Reasons for Implementing ERP}

The outcomes reveal an ensemble of substantive, institutional and political factors (we will clarify this reason typology later in the discussion). The main reason for implementing ERP was the "need to integrate the organization's processes and information", a substantive reason. The other leading answers were "the need to follow a trend" (an institutional reason), followed by "the need to meet the pressures of the IT function", and "the pressures of the head office" (both political reasons).

Additionally, a high percentage of respondents recognized that "the firm didn't know exactly what it was buying" nor "what could be expected from the system". These types of outcomes are similar to conditions commonly associated with the adoption of managerial fads and fashions; that is, a considerable pressure form diffusion agents and institutional actors, coupled with a high level of emotional content in the decision making process.

\section{Implementation Approach and Focus}

Results suggest that several distinct practices may exist in terms of the implementation method: whereas $44 \%$ stated that it was consensual, $41 \%$ of the respondents cited that it was imposed. In either case, $30 \%$ of the respondents said that user involvement was low or insufficient. Similar diversity could be observed regarding the implementation approach: $24 \%$ affirmed that the process was focused on its human side and on its transformational dimension, whereas $36 \%$ admitted that the process was more heavily focused on information technology. 
In most companies (71\%), implementation followed reengineering, or was conducted simultaneously with reengineering. But only $34 \%$ of respondents declared that the reengineering process was conducted in depth.

The use of external support was also surveyed: $91 \%$ of the implementation processes were conducted using assistance of management consultants. However, only $47 \%$ of all respondents claimed that the consulting firm was operative and influential during the implementation process, and no more than $23 \%$ cited that the consultants had the necessary skills and experience.

These outcomes revealed a remarkable diversity in terms of perspectives. Many organizations seem to perceive ERP implementation merely as another IT project, and not as a major organizational transformation. One could suppose that part of the reason for such limited approach derives from the pressures for adoption coming from IT personnel. This is what we have termed techno-reductionism.

It was also revealed that some organizations seemed to adopt an expanded approach, i.e., one that considers the ERP implementation as some type of "ITmeets-reengineering-project". However, it should also be mentioned that a significant part of respondents considered the reengineering process that their ERP implementation contained as quite superficial. This is what we have termed systemic-reductionism.

When they did not realize the impact ERP implementation would have on people and management, several organizations not only failed to generate the gains of a deeper organizational transformation, but they also have put themselves at risk, by ignoring the interactions between ERP and other organizational dimensions and variables. During such interventions, the more one restricts the implementation approach, the more pernicious one may expect the side effects to be in the organization as a whole.

\section{Outcomes of the Implementation}

The overall perception of the respondents in the sample is that the implementation generated significant improvements to their organization. However, one cannot mention unanimity, and when analyzing specific issues, it is possible to verify significant levels of frustration. For example: $45 \%$ of the respondents did not perceive any improvements whatsoever in terms of competitive advantage; $43 \%$ affirmed that no cycle time reductions were obtained; and $40 \%$ admit that there were no gains in customer service. Moreover, several negative effects were cited in significant percentages, particularly relating to issues such as flexibility and costs. 
On the other hand, several respondents reported significant gains from the implementation. The main advantages quoted in the open questions were increased integration amid areas and sites; increased information integration and process integration; improvement on the quality of information; favorable opportunity to rethink processes; and improved level of control.

As to the disadvantages cited in the open questions, the most significant were that ERP failed to tailor itself to the specific needs of the organization; loss of key organizational functions, due to system requirements; superficial process redesign; high dependency of a single software provider; and excessive control.

To many respondents, the implementation was a painstaking job, usually characterized by scope and planning mistakes. Nonetheless, of all respondents, $91 \%$ concluded that, if given the opportunity to decide again, the organization would once more choose to implement the ERP system. However, $25 \%$ of them said they would significantly change the scope and/or the implementation approach, if given the chance.

Remarkably, the low impact of the ERP implementation on items such as competitive differentiation and costs denounces the existence of serious problems in many implementations. Also noteworthy are some disadvantages pointed out by respondents such as low adaptation levels between the system and specific business needs, which may lead to the loss of some strategic functions and information, as has already been predicted by theorists and noted by practitioners (e.g., Davenport, 1998). Paradoxically, most of the respondents in the survey seem to agree that there is no alternative to the ERP trend, and that the outcomes are mainly positive. Although it seems undeniable that for many organizations a successful ERP implementation has indeed solved substantive problems and/or operational deficiencies, the survey also reveals flaws in this type of not-necessarilygrounded-consensus.

It is precisely at this point that it seems appropriate to point out the political and institutional context surrounding ERP implementations. If we combine, on the one hand, the strong political and institutional drivers which will be discussed in the next section, and on the other, the immense investments involved and the high hopes concerning the outcomes of the ERP project, one may expect it all to impair a critical assessment significantly. In fact, one could state that there are many stimuli to lip-service (i.e., ceremonial) behavior (Meyer and Rowan, 1977; Caldas and Wood, 1997). Thus, even when results may be deceiving, assessments could remain mostly positive. 


\section{Trying to Make some Sense out of the ERP Craze}

We believe that the practice of management, as well as ERP implementation efforts, can largely benefit from the use of a broader perspective to its comprehension, one that could challenge the reductionism and information technology biases that have characterized the prevailing approach on the subject. In the present section, we will propose one such broader, alternative, perspective on the ERP phenomenon.

The perspective we pose arises from the confluence of three sets of factors already mentioned in the text: substantive factors, institutional factors, and political factors. All these factors interact with each other, creating a complex dynamic process. All three, alone and combined, at the end influence (1) the adoption, (2) the implementation approach, and (3) the assessment of ERP in organizations.

\section{Substantive Factors}

Substantive factors comprise all real imperatives, problems and opportunities that organizations face and for which ERP may constitute an adequate and effective response. They are generally mentioned in the technical literature, in brochures of management consulting firms. Among them, one may list:

. The growing need to integrate the operations of multinational companies: most multinational organizations are striving to integrate their global operations. Such integration is perceived as necessary for at least two sets of reasons: firstly, because by integrating their operations they can rapidly diffuse innovations globally, deploy international best practices, and further leverage their scale and global competitive advantage; and secondly, because by integrating their information systems, they believe they can more efficiently manage and control key investments, strategic resources, as well as main decisions across borders.

Permanent pressure to reduce costs and improve efficiency: this driver also demands a high level of information integration. Such integration would allow systemic improvements, which would result from shorter customer service and fulfillment cycles, reduction of logistical costs and inventory cutback. Other examples of this type of integration opportunity include: reduction of headcount and inventory, standardization of process design and of hardware and software configurations, minimization of systems integration costs and IT personnel, and reduction on the use and expense with materials. 
. Significant trend toward the adoption of process-based management models: for the past few years, it seems undeniable that process-based structures and models have deeply influenced organizations before and beyond the reengineering fad. However, a typical barrier to the thorough implementation of this perspective has been the difficulty to integrate information and information systems across the organization. Hence, ERP meets the primary requirement of most primary management models and operational templates that are in use today, sharing their same process-based perspective on work design.

\section{. Emergence of information technology architectures that make integration possible: this enabler granted the technological basis, including client-server architectures and data-sharing technology, that provides the means to the existence of modern ERP.}

\section{Institutional Factors}

Institutional factors comprise all external forces existing in the organizational environment, which pressure the adoption of ERP. Institutional factors are commonly discussed in the literature on management fads and fashions. Such literature analyzes how fads are created and tend to generate cycles of management panaceas (Gill and Whittle, 1992), their patterns of diffusion and rejection in organizations (Caldas and Wood, 1995; Caldas, 1996; Abrahamson and Fairchild, 1997) and reasons for adoption of new managerial technology in organizations (Abrahamson, 1991, 1996). Viewed from this standpoint, ERP can be perceived as the successors of other management panaceas as TQM, downsizing and reengineering. In the case of ERP, the most significant institutional factors can be grouped as follows:

Interests of primary diffusion agents: primary diffusion agents are those involved in the creation of new management technologies and fads, firms that survive directly and almost exclusively from the revenues generated by their diffusion. In the case of ERP, such agents naturally include: (1) vendors of ERP hardware e software; and (2) consulting firms seeking business generated by pre-implementation, implementation, and post-implementation opportunities.

. Interests of secondary diffusion agents: secondary diffusion agents are those that live on the edge of the market created by management fads, and include individuals and organizations that profit indirectly from their diffusion. In the case of ERP, such agents include: (1) technical and business media, which tend to have a significant interest by the business that the ERP issue can produce; (2) management gurus and business book publishers, for whom ERP defines an attractively growing market niche; and (3) business schools, training 
organizations and seminar promoters, which nourish the escalating demand for technical instruction and information on ERP.

The combined influence of these two types of diffusion agents generates a strong isomorphic pressure, that pushes each organization to comply to institutionalized (i.e., socially legitimated) management practices. A good deal of the so-called neoinstitutional literature (e.g., Meyer and Rowan, 1977; DiMaggio and Powell, 1983; Scott, 1987) has attempted to explain why organizational practices - as is the case nowadays with ERP - may end up as a standard practice within vast institutional fields, be it by its imposition (coercive isomorphism), by its social legitimization (normative isomorphism), or by imitation (mimetic isomorphism).

\section{Political Factors}

Political factors reflect the interests of power groups and coalitions inside the organization. They relate to those organizational needs for which ERP does not pose direct solutions, but for which ERP are an ideal means of obtaining a solution, or even its associated outcome. Despite their relevance, political factors are seldom mentioned in the literature on managerial innovations (e.g., Frost and Egri, 1991), let alone on ERP (e.g., Brown, 1998; Davenport, 1998). Typically, the most significant political factors are:

. Centralization interests: ERP may be used by the strategic apex (i.e., top management), or by managers connected to corporate functions, to centralize decision making and to increase control over subsidiaries or business units.

- Standardization and concentration interests: managers at corporate areas and functions can take advantage of ERP to enforce the standardization of processes and operations - and potentially their concentration as shared staff functions - that otherwise would remain autonomously designed at the subsidiary or business unit level.

. Interest of power groups and coalitions: the implementation of ERP may result in profound changes in work design, organizational structure and internal power configuration. Hence, an ERP implementation may become an arena in which several groups battle seeking not only to control the project - an obvious source of power and influence - but also to expand their influence amid the turbulence that the transformation will probably bring about.

- IT departments' quest to regain power: the information technology function gave in quite a lot of ground in organizations over the last decade, due to the 
system decentralization (which followed technological downsizing) and outsourcing movements. An ERP implementation can certainly represent an opportunity for such departments to regain lost authority and influence.

Altogether, those factors - substantive, institutional, and political - are closely connected. Substantive factors - generally influenced by contextual conditions influence both institutional and political factors. On the one hand, they generate the demand for solutions (production of innovations) activating institutional factors, and on the other, they provide the concrete arguments to validate internal justification (political factors) within organizations.

Institutional factors also influence political and substantive factors. Such influence occurs, firstly, because institutional factors provide legitimized vehicles to justify political factors, granting interest groups with a management technique they can take advantage of in their own benefit; and secondly, because institutional factors end up reinforcing most substantive factors, by giving them an image of particular urgency and relevance.

And lastly, political factors also influence substantive and institutional factors. They influence all substantive factors by giving them a sense of propriety and sufficiency, which was attributed to ERP by internal groups in their own behalf. And they also reinforce institutional factors, by nurturing diffusion agents that will serve the purposes of power groups within the organization, and by reinforcing the idea of inevitability of the ERP adoption trend.

Whereas the current reductionist discourse on ERP concentrates solely on substantive factors, we believe that the ERP phenomenon can only be understood if it is also perceived in terms of the institutional and political factors which concur to define it, within and around the organization.

\section{Complex Thinking: Interacting Parts and the Whole}

In this section, we will return to the theoretical discussion on reductionism and complex thinking, focusing mainly on Organization Studies. Based on such concepts, we will discuss the amplitude of changes involved in the adoption of ERP. Toward the end of the section, we will raise conjecture on the reasons for the predominance of reductionist reasoning during processes of adoption and implementation of ERP systems. 


\section{Reductionism, Systemic Reductionism, and Complex Thinking}

As we discussed earlier in the paper, the term reductionism refers to the practice of dividing the whole into its constituent parts, and then studying them separately (Flew, 1984). On the other hand, the term holism refers to the study of the whole with no division (Beed and Beed, 1996). Systemic thinking is basically an holistic conception, popularized since the 1950s by Ludwig Von Bertalanffy in his General Systems Theory (Bertalanffy, 1968).

According to Piaget (1967), reductionism is the tendency to reduce the complex to the simple, whereas antireductionism reflects the tendency to draw the existence of irreducible structures that could not be reduced to more simple elements (Landry, 1995).

In Western culture, we have conditioned ourselves to think in a reductionist and linear fashion. However, when we came upon the idea of systems, our reductionist blurring tended to be substituted by an holistic blurring, one that is only able to see the whole (Mariotti, 1999). Thus, we oscillate between one extreme and the other.

Alternatively, complex thinking constitutes yet another way of perceiving totality (e.g., Morin, 1977). Its fundamental principle is the complementary nature between the reductionist conception and the holistic conception. A fundamental characteristic of complex thinking, when applied to the study of systems, is the interchanging between superiority and inferiority of the whole in relation to the sum of the parts. When the system behaves in an orchestrated and convergent manner in order to generate an output that exceeds the sum of the parts, one says that the system is in superiority mode. Alternatively, when the individual potentialities of the parts are restricted in the name of overall harmony, one says that the system is on inferiority mode.

Therefore, from the standpoint of complexity, systems are dynamic and transact continuously between one mode and the other, and hence it is impossible to determine at any given moment whether it is in superiority or inferiority mode.

What derives from this line of reasoning is that the harmony of the system occurs because of the repression of parts' potentialities and the suppression of eventual antagonisms. It is, as a result, harmony built on conflict. The successful functioning of complex systems, like organizations, will depend fundamentally on the balance between these two states: one favoring individuality, and the other favoring totality. The former will make creativity and renewal possible, whereas the latter will guarantee the system's own subsistence. 
Essentially, complex systems must deal with uncertainty. Conversely, human beings seem to cultivate a constant quest for certainties. Such a wish may justify the popularity of ERP systems, with their promises of control, consistency and reliability.

Many times, when one talks about systemic thinking, including in Organization Studies, one may be in fact referring to a distortion that does not take into account the concept of complexity. One imagines that a system is merely a collection of interdependent parts, and that their sum is superior to the whole. When there is reference to systemic complexity, there seems to be a certain amount of confusion between complexity and complication. A complexity to be understood and worked on is substituted by a complication that needs simplifying. This is what we have called systemic reductionism.

\section{Reductionism and Organization Studies}

In Organization Studies, the discussion on reductionism, systemic vision and complex reasoning can be associated with the so-called paradigm wars, which took place mostly during the 1980s (Burrell and Morgan, 1979; Morgan, 1986; Burrell, 1996). Such a debate placed objectivist approaches and subjectivist approaches on opposite sides, as well as usually correlating reductionism with objectivist tradition. The criticism concerning reductionist perspectives has been present, although not always explicitly, among theorists ranging from organizational environmentalism (e.g., Soderbaum, 1993; Meima, 1996) to applied psychology (e.g., Lyng, 1988). For its critics, the main argument against reductionism is the oversimplification of organizational phenomena (e.g., Burrell and Morgan, 1979; Morgan, 1986; Williams, 1996).

The specific case at hand, technological reductionism, has been covered before in Organization Studies. Hodgson $(1985,1988)$, for example, has criticized those, as he sees the case of Kay $(1984,1988)$, who reduce almost every problem to one of information. The argument is that informational reductionism inhibits the recognition of the difference between conscious and unconscious processes and the perceptual, cognitive, and conceptual processes involved in decision making and organizational reality.

\section{ERP: It's not only about IT, it's about IT plus Change}

In this paper, one of our main arguments is that the changes involved in an ERP implementation transcend the IT domain. The reason for this is that ERP implementations may provoke considerable impacts on organizational design, on 
the management model, on the interaction among individuals and groups, on the definition of autonomy and authority limits, on managerial style, and even on the organization's strategic process.

At best, to perceive an ERP implementation as a simple software implementation may reduce its potential to drive organizational transformation. At worst, it may submerge the organization in a blinded change process, in which the impact on the dimensions mentioned above is frequently ignored. In this case, the ERP implementation may evolve into an incoherent and endless process of small adjustments to the organization to force its fittings to the system's requirements.

In our field survey, several respondents did mention negative effects of the implementation, such as the loss of strategic functions, lack of flexibility of management and organization models, etc. Indeed, those features are at the very core of the competitive position of organizations, and are crucial in any coherent organizational transformation move. Such results should serve as an warning to the risks that organizations adopting ERP are taking when embracing a reductionist approach.

\section{Why Reductionism?}

The question that needs to be answered is: what leads so many organizations to adopt a techno-reductionist or systemic-reductionist perspective during the implementation of ERP? Based on the field survey, we believe five factors may answer such question.

The first factor is the predominance of reductionist thinking in our culture. As pointed out by Mariotti (1999), our mind is formatted to think in a linear and reductionist manner. In fact, such a condition seems to reflect the spirit of our times. Crushed by the acceleration and by the increase in connectivity in the business environment, many executives and consultants tend to adopt monotonic and simplistic discourses. The result is the proliferation of 7-bullets programs and self-help managerial books. However, as the French anthropologist Claude Levy-Strauss once remarked, the task should not be one of reducing the complex, ripping it from its vital parts, but one of making complexity intelligible and treatable.

The second factor is the limited information about organizational transformation. Many implementation agents (e.g., large consulting firms - or even consulting practices focused solely on IT consulting within large consulting firms), as well as many executives responsible for such implementations, simply have no systemic vision of the variables involved in a broad organizational transformation. Alternatively, many of those implementation agents and executives 
do not perceive ERP implementations as change processes. Therefore, they act upon certain parts without realizing or giving proper importance to others, or to the whole.

The third factor is the inhibition caused by the difficulty to sell and to conduct large organizational transformation processes. Some consultants do perceive ERP implementations as complex and comprehensive processes. However, they seldom can - or even attempt to - make such a vision explicit to their clients. The same happens among executives. To sell large organizational transformation processes from outside (as is the case of consultants) or internally (as is the case of executives) can be a truly laborious task. On that account, many consultants and executives are afraid of losing business or support for their projects if its complexity is thoroughly realized.

The fourth factor is the aggressive communication of diffusion agents, and it is directly related to the institutional elements. After many year of exposure to the rhetoric of consultants, software and hardware suppliers, and business media, many decision makers seem to have assimilated their discourse. It happens that such discourse is almost inevitably reductionist. To sell their services, many consultants, as well as software and hardware vendors, utilize dramatic and reductionist communication (Lampel, 1995). The same occurs frequently among business journalists. To make news interesting to their readers, such professionals at times rebuild reality from fragments of information they judge to be more appealing. This process ends up being reproduced within organizations, when internal change agents reproduce the discourse of external agents to overcome resistance to change.

The fifth factor relates to interests of power groups within the organization, and is closely connected to the political factors. Power groups may be politically interested in conducting or influencing the ERP implementation. Such a position may materialize as an appropriation or manipulation of specific discourses. This sensorial articulation has usually a reductionist character, since it underlines certain dimensions interesting to the group, overruling or reducing the importance of others.

Altogether, these factors result in a barrier to the development of non-reductionist reasoning. The possible evolution, which some organizational development and change consultants have realized and many executives have accepted, has been in the general direction of adding to ERP implementations a few initiatives such as communication plans, change awareness workshops, user training and, sometimes, (superficial) revision of organizational architecture. This denotes what we have called systemic reductionism. 


\section{Final Comments}

In this paper we stated that ERP should be understood as a complex phenomenon that comprises and produces significant transformational implications for organizations. We argued that many organizations are taking large interventions they have been conducting - as is nowadays the case of ERP implementation from a reductionist perspective.

As an alternative, we have proposed the use of a broader perspective - which we exercise to understand the ERP phenomenon - that comprehends substantive, political, and institutional dimensions. Using such a perspective, several determinants of the ERP craze arose.

Recent ERP diffusion has been bolstered by an intense institutional apparatus. Such environment inhibits reflection and is characterized by low level of criticism. The most common outcome is the proliferation of failures in implementation, growing dissatisfaction, and serious, long-term implications non-technological dimensions of organizations.

We thus recommend that ERP implementations should be understood as major organizational change processes, and hence that they should be planned and conducted as such, within a non-reductionist view. We consider this paper an initial study, to be followed by further discussion and empirical research.

\section{REFERENCES}

\section{ABRAHAMSON, E.}

Managerial fads and fashions : the diffusion and rejection of innovations. Academy of Management Review, v. 16, p. 586-612, 1991.

Management fashion. Academy of Management Review, v. 21, n. 1, p. 254-285, 1996.
ABRAHAMSON, E.;

FAIRCHILD, G.

Management fashion : lifecycles, triggers, and collective learning processes. In: ANNUAL MEETINGS OF THE ACADEMY OF MANAGEMENT (1997 : Boston). Proceedings... Boston, MA : [s.n.], 1997. 
AMR RESEARCH.

AMR research predicts industrial enterprise applications market will reach \$72.6 billion by 2002. Press Release. Boston, MA, Nov. 1998.

BEED, C.;

BEED, C.

Polarities between naturalism and non-naturalism in contemporary economics : an overview. Journal of Economic Issues, v. 30, n. 4, p. 1077-1104, 1996.

BERTALANFFY, L. V.

General systems theory. New York : Georges Braziller, 1968.

BROWN, A. D.

Narrative, politics and legitimacy in an IT implementation. Journal of Management Studies, v. 35, n. 1, p. 35-58, 1998.

BURRELL, G.;

MORGAN, G.

Sociological paradigms and organizational analysis. London: Heinemann Educational Books, 1979.

BUSINESSWEEK.

SAP, o espírito do Vale do Silício chega ao Reno. Gazeta Mercantil, 17 de nov. 1998. C6-C7.
CALDAS, M. P.

Toward a more comprehensive model of managerial innovation diffusion : why consultants are not the only ones to blame. In: ANNUAL MEETINGS OF THE ACADEMY $\mathrm{OF}$ MANAGEMENT (1996: Cincinnati). Proceedings... Cincinnati : [s.n.], 1996.

CALDAS, M. P.;

WOOD JR., T.

Inovações gerenciais em ambientes turbulentos. In: WOOD JR., T. (Ed.). Mudança organizacional : aprofundando temas atuais em administração de empresas. São Paulo : Atlas, 1995.

For the english to see : the importation of managerial technology in late $20^{\text {th }}$ century Brazil. Organization, v. 4, n. 4, p. 517-534, 1997.

CARVALHO, L. R. M.

Integrated systems implementation. In: $1^{\text {st }}$ SIMPOI (1998 : São Paulo). Proceedings... São Paulo : EAESP/FGV, 1998. p. 273-287.

CORREA, H. L.

ERPs : por que as implantações são tão caras e raramente dão certo? In: $1^{\text {st }}$ SIMPOI (1998 : São Paulo). Proceedings... São Paulo : EAESP/FGV, 1998. p. 288300. 
DAVENPORT, T. H.

Putting the enterprise into the enterprise system. Harvard Business Review, p. 121-131, July/Aug. 1998.

DIMAGGIO, P. J.;

POWELL, W. W.

The iron cage revisited : institutional isomorphism and collective rationality in organizational fields. American Sociological Review, v. 48, p. 147-160, 1983.

FLEW, A. (Ed.).

A dictionary of philosophy. 2 . ed. London: Pan/MacMillan, 1984.

FROST, P. J.;

EGRI, C. P.

The political process of innovation. In: STAW; CUMMINGS (Eds.). Research in organizational behavior. Greenwich : JAI Press, 1991. v. 13.

\section{GILL, J.;}

WHITTLE, S.

Management by panacea : accounting for transience. Journal of Management Studies, v. 30, n. 2, p. 281-295, 1992.

\section{HODGSON, G.}

The rationalist conception of action. Journal of Economic Issues, v. 19, p. 825-851, Dec. 1985.
On informational reductionism : a reply to Kay. Journal of Economic Issues, v. 22, n.1, p. 244, 1988.

KAY, N. M.

The emerging firm : knowledge, ignorance and surprise in economic organization. London : Macmillan, 1984.

Three different ways to tie your shoelaces : comment on Hodgson. Journal of Economic Issues, v. 22, n. 1, p. 233-244, 1988.

LAMPEL, J.

Innovation as spectacle : dramaturgical construction of technological change. In: CONFERENCE ON THE SOCIAL CONSTRUCTION OF INDUSTRIES AND MARKETS (1995 : Chicago). Proceedings... Chicago : [s.n.], 1995.

LANDRY, M.

A note on the concept of 'problem'. Organization Studies, v. 16, n. 2, p. 315, 1995.

LYNG, S.

Holism and reductionism within applied behavioral science : the problem of clinical medicine. The Journal of Applied Behavioral Science, v. 24, n.1, p. 101-117, 1988. 
MARIOTTI, H.

Reducionismo, 'holismo' e pensamentos sistêmico e complexo. [online] Disponível na Internet via WWW.URL : http:// www.geocities.com/complexidade. 1999.

MCGEE, J.;

PYBURN, L.;

PRUZAK, L.

Managing information strategically. New York : John Wiley \& Sons, 1993.

MEIMA, R.

Epistemological problems and a proposal for dichotomous approach. Academy of Management Review, v. 21, n. 4,p. 914-917, 1996.

MEYER, J. W.;

ROWAN, B.

Institutional organizations : formal structure as myth and ceremony. American Journal of Sociology, v. 83, p. 340-363, 1977.

MINTZBERG, H.

Structure in fives : designing effective organizations. Englewood Cliff, NJ : PrenticeHall, 1983.

MORGAN, G.

Images of organization. London: Sage Publications, 1986.
MORIN, E.

La méthode. Paris : Seuil, 1977.

PIAGET, J.

Les methodes de l'epistemologie' in logique et connaissance scientifique. In: PIAGET, J. (Ed.). 62131. Paris : Gallimard, 1967.

ROGERS, E.

Diffusion of innovation. New York : Free Press, 1983.

SCOTT, W. R.

The adolescence of institutional theory. Administrative Science Quarterly, v. 32, p. 493-511, 1987.

SODERBAUM, P.

Values, markets, and environmental policy : an actornetwork approach. Journal of Economic Issues, v. 27, n. 2, p. 387-408, 1983.

VAN DE VEN, A. H.

Central problems in the management of innovation. Management Science, v. 22, n. 5, p. 590-607, 1986.

WILLIAMS, T.

Dividing up reality. Futures, v. 28, n. 9, p. 873-878, 1996. 